\title{
The MIPAS HOCl climatology
}

\author{
T. von Clarmann ${ }^{1}$, B. Funke ${ }^{2}$, N. Glatthor ${ }^{1}$, S. Kellmann ${ }^{1}$, M. Kiefer ${ }^{1}$, O. Kirner ${ }^{3}$, B.-M. Sinnhuber ${ }^{1}$, and G. P. Stiller ${ }^{1}$ \\ ${ }^{1}$ Karlsruhe Institute of Technology, Institute for Meteorology and Climate Research, Karlsruhe, Germany \\ ${ }^{2}$ Instituto de Astrofísica de Andalucía, CSIC, Granada, Spain \\ ${ }^{3}$ Karlsruhe Institute of Technology, Steinbuch Centre for Computing, Karlsruhe, Germany \\ Correspondence to: T. von Clarmann (thomas.clarmann@ kit.edu)
}

Received: 1 June 2011 - Published in Atmos. Chem. Phys. Discuss.: 22 July 2011

Revised: 26 January 2012 - Accepted: 3 February 2012 - Published: 20 February 2012

Abstract. Monthly zonal mean $\mathrm{HOCl}$ measurements by the Michelson Interferometer for Passive Atmospheric Sounding (MIPAS) are presented for the period from June 2002 to March 2004. Highest molar mixing ratios are found at pressure levels between 6 and $2 \mathrm{hPa}$, whereby largest mixing ratios occasionally exceed $200 \mathrm{ppt}$. The mixing ratio maximum is generally higher at lower altitudes in the summer hemisphere than in the winter hemisphere except for chlorine activation conditions in polar vortices, where enhanced $\mathrm{HOCl}$ abundances are also found in the lower stratosphere below about $10 \mathrm{hPa}$. During nighttime the maximum is found at higher altitudes than during daytime. Particularly low values (below $80 \mathrm{ppt}$ ) during daytime are found in subpolar regions in the winter hemisphere where $\mathrm{HOCl}$ photolysis is still strong but where $\mathrm{HOCl}$ precursors are less abundant than at other latitudes. The Antarctic polar winter $\mathrm{HOCl}$ distribution in 2002, the year of the split of the southern polar vortex, resembles northern polar winters rather than other southern polar winters. Increased $\mathrm{HOCl}$ amounts in response to the so-called Halloween solar proton event in autumn 2003 affect the representativeness of data recorded during this particular episode. Calculations with the EMAC model reproduce the measured $\mathrm{HOCl}$ distribution reasonably well. MIPAS measurements confirm that the reaction rate constants for $\mathrm{HO}_{2}+\mathrm{ClO} \longrightarrow \mathrm{HOCl}+\mathrm{O}_{2}$ from the most recent JPL recommendation allow much more realistic modelling of $\mathrm{HOCl}$ than reaction rate constants from earlier recommendations. Modeled $\mathrm{HOCl}$ mixing ratios, however, are still too low except in the polar winter stratosphere where the model overestimates the $\mathrm{HOCl}$ abundance.

\section{Introduction}

$\mathrm{HOCl}$ is a short-lived reservoir of $\mathrm{ClO}_{\mathrm{x}}$ and $\mathrm{HO}_{\mathrm{x}}$ and thus links stratospheric chlorine and odd hydrogen chemistry. The $\mathrm{HOCl}$ catalytic cycle is an important mechanism for midlatitude stratospheric ozone loss (Daniel et al., 1999; Millard et al., 2003). In the polar vortices $\mathrm{HOCl}$ has heterogeneous sources and sinks and thus can contribute to the polar chlorine chemistry (Hanson and Ravishankara, 1992; Abbatt and Molina, 1992; Crutzen et al., 1992; Prather, 1992; von Clarmann et al., 2009a). It also serves as indicator for perturbed $\mathrm{HO}_{\mathrm{x}}$ chemistry (von Clarmann et al., 2005). Occasional $\mathrm{HOCl}$ measurements exist from balloon-, space-, and airborne infrared solar absorption experiments (Larsen et al., 1985; Toon et al., 1992; Raper et al., 1987), balloonborne far infrared limb emission (Chance et al., 1989; Traub et al., 1990; Johnson et al., 1995), as well as balloon-borne infrared limb emission (von Clarmann et al., 1997) measurements. The MIPAS (Michelson Interferometer for Passive Atmospheric Sounding) onboard Envisat provided the first global HOCl data set (von Clarmann et al., 2006). Further global $\mathrm{HOCl}$ measurements have been provided by the Microwave Limb Sounder (MLS) (Cofield and Stek, 2006) and JEM/SMILES (Kasai et al., 2009; Kikuchi et al., 2010; Baron et al., 2011).

Large discrepancies between measured and modeled $\mathrm{HOCl}$ abundances were found by Kovalenko et al. (2007), suggesting that reaction rate coefficients for $\mathrm{HOCl}$ formation from $\mathrm{ClO}$ and $\mathrm{HO}_{2}$ as published by Stimpfle et al. (1979) might be more appropriate than the JPL-2006 recommendation valid at that time (Sander et al., 2006). This has been 
confirmed by von Clarmann et al. (2009a) and is also stated in World Meteorological Organization (2011). Since then these rate constants have been revised in the most recent JPL recommendation (Sander et al., 2010).

In this paper we present the first climatology of global altitude-resolved $\mathrm{HOCl}$ measurements, covering a full annual cycle, based on MIPAS measurements and compare these data to model calculations based on different rate coefficients of $\mathrm{HOCl}$ formation, including those by Stimpfle et al. (1979), Sander et al. (2006), and the most recent JPL recommendation by Sander et al. (2010).

\section{MIPAS HOCl data}

MIPAS is a Fourier transform limb emission spectrometer operated to measure vertical profiles of temperature and mixing ratios of many trace species (Fischer et al., 2008). MIPAS is one of three atmospheric chemistry related instruments on the Envisat research satellite. Envisat has been launched in a sun-synchroneous polar orbit of about $800 \mathrm{~km}$ altitude, $98.55^{\circ}$ inclination, orbital period of $100.6 \mathrm{~min}$, and equator crossing at approximately 10:00 LT (local time). In its original nominal measurement mode MIPAS recorded one set of 17 limb measurements at tangent altitudes from 6 to $68 \mathrm{~km}$ per $76.5 \mathrm{~s}$, i.e. per $510 \mathrm{~km}$ ground track at a spectral resolution of $0.05 \mathrm{~cm}^{-1}$ apodized. After failure of the interferometer slide, regular operation was interrupted in 2004. Since 2005 MIPAS is operational again, however at reduced spectral but improved spatial resolution. While for many trace species the change of operation mode turned out to be advantageous in terms of precision, altitude-, and along-track horizontal resolution (Chauhan et al., 2009; von Clarmann et al., 2009b), HOCl could not yet successfully be retrieved from these reduced resolution measurements, because its lines could not be well enough resolved among the much stronger lines of interfering species. Thus MIPAS $\mathrm{HOCl}$ retrievals are available only from June 2002 to March 2004.

$\mathrm{HOCl}$ is retrieved from MIPAS spectra using the IMK/IAA scientific MIPAS processor (von Clarmann et al., 2003) by constrained least-squares fitting of simulated to measured spectral radiances. Details of the retrieval settings are discussed in von Clarmann et al. (2006). A Tikhonovtype first order finite differences constraint, modified to allow an altitude-dependent choice of the strength of the regularization (Steck and von Clarmann, 2001) has been chosen in order to avoid biasing of retrievals towards the a priori information. The measurement error was found to be largely dominated by measurement noise. The precision of a single profile measurement is estimated at 30 to $80 \mathrm{ppt}$, i.e. about $25 \%$ of the peak molar mixing ratio. The altitude resolution is about $9 \mathrm{~km}$, due to the strong smoothing constraint needed to obtain stable retrievals at low signal/noise ratio. MIPAS averaging kernels are shown in Fig. 1. They are well-behaved in an altitude-range between about 20 and $45 \mathrm{~km}$, in a sense that they are approximately symmetric around their nominal altitudes. In this altitude region the MIPAS $\mathrm{HOCl}$ profiles can be regarded as a smoothed version of the true $\mathrm{HOCl}$ profiles. At altitudes above $45 \mathrm{~km}$ and below $20 \mathrm{~km}$ the sensitivity of the MIPAS $\mathrm{HOCl}$ retrievals is largely reduced, and the asymmetric averaging kernels shift information from these altitudes into the altitude range where MIPAS is sensitive. In the presence of $\mathrm{HOCl}$ at these altitudes, application of the MIPAS averaging kernels is thus particularly important to make high-resolution model results comparable to MIPAS measurements (cf., e.g. Jackman et al., 2008). Since the MIPAS a priori profiles are zero throughout, this transformation reduces to

$\boldsymbol{x}_{\text {degraded }}=\mathbf{A} \boldsymbol{x}_{\text {fine }}$,

where $\boldsymbol{x}_{\text {fine }}$ is the high-resolution $\mathrm{HOCl}$ profile, $\boldsymbol{x}_{\text {degraded }}$ is the degraded profile which should be used for the comparison, and $\mathbf{A}$ is the MIPAS averaging kernel matrix. MIPAS averaging kernels have the quite same structure and characteristics for all seasons and latitude bands; small to moderate differences reflect the seasonal and latitudinal temperature variation. No substantial differences between daytime and nighttime averaging kernels are observed. This is because at relevant altitudes the atmosphere is rather transparent, leading to linear radiative transfer and thus independence of the Jacobians (and thus averaging kernels) from the actual mixing ratio of $\mathrm{HOCl}$. Beyond random error and smoothing effects, the systematic error due to uncertainties of spectroscopic data contributes to the total error budget. It is estimated at $10 \%$ (von Clarmann et al., 2006).

MIPAS zonal mean $\mathrm{HOCl}$ mixing ratios were found to agree within one standard deviation with trendcorrected balloon-borne far-infrared measurements reported by Chance et al. (1989, 1996) (von Clarmann et al., 2006). The most recent version of MIPAS $\mathrm{HOCl}$ data is V3O_HOCl_4. Improvements with respect to previous data versions are obtained by consideration of horizontal temperature gradients, stronger regularization of $\mathrm{N}_{2} \mathrm{O}$ profiles which are jointly fitted, a finer monochromatic wavenumber grid used in the radiative transfer calculation, a larger number of pencil beams for radiance integration over the instantaneous field of view, and some updates of spectroscopic data of gases used in the radiative transfer calculations. V3O_HOCl_4 data agree well with earlier data versions and none of the improvements has led to any major changes in the results. These data are availavle via http://www.imk-asf.kit.edu/english/308.php to registered users.

\section{Method}

MIPAS HOCl climatologies have been prepared in compliance with the methodical and data format requirements of the SPARC (Stratospheric Processes and their Role in Climate) Data Initiative (Hegglin and Tegtmeier, 2011). The 


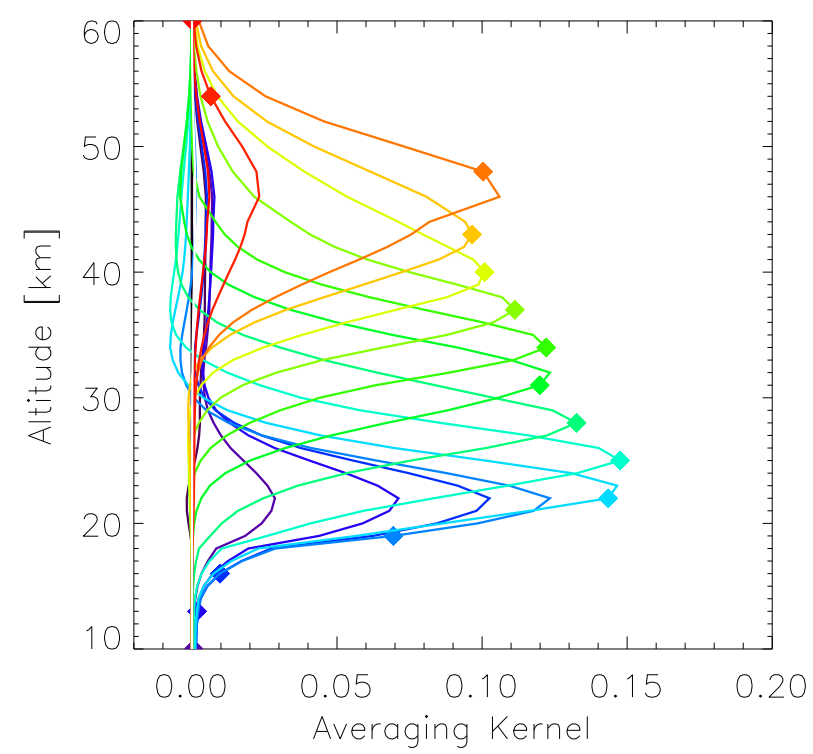

Fig. 1. Averaging kernels of MIPAS HOCl measurements. Diamonds represent the nominal altitudes (i.e. the diagonal value of the averaging kernel matrix). For clarity, only every third averaging kernel is shown. This example refers to a profile measured during night at $27.9^{\circ} \mathrm{S}, 86,2^{\circ} \mathrm{E}$ on 1 January $2003,16: 34 \mathrm{UT}$.

climatology consists of zonal monthly mean fields of $\mathrm{HOCl}$ molar mixing ratios and their standard deviations and sample sizes. In order to account for the diurnal variability of $\mathrm{HOCl}$, separate mean fields are provided for a.m. and p.m. measurements. The altitude grid is $300,250,200,170,150,130,115$, $100,90,80,70,50,30,20,15,10,7,5,3,2,1.5,1.0,0.7$, $0.5,0.3,0.2,0.15,0.1 \mathrm{hPa}$, and the centers of the equidistant latitude bins are $-87.5^{\circ},-82.5^{\circ}, \ldots, 82.5^{\circ}, 87.5^{\circ}$. Each profile was first interpolated to the pressure grid using MIPAS pressure and temperature profiles (von Clarmann et al., 2006) and then averaged. Since MIPAS measured one profile each $510 \mathrm{~km}$ ground track distance from a polar orbit, only one or two profiles per orbit segment fall within a latitude bin. Since the measurement sequence is re-initialized at a fixed latitude during each orbit, this leads to a systematic sampling bias, i.e. the MIPAS measurement does not generally represent the nominal central latitude of the latitude bin. In order to avoid related artefacts, it has been decided to linearly interpolate the MIPAS measurements to the nominal latitudes. Standard deviations and the number of measurements are provided along with the molar mixing ratios. The number of profile measurements per monthly zonal mean and time of the day (a.m. or p.m.) was typically between 400 and 800 . Since the interpolation of these quantities to the nominal latitude grid is not a trivial task, particularly if both measurement errors and natural variability contribute to the variance, related operations are discussed in detail in Appendix A.

\section{Model calculations}

In order to assess how well $\mathrm{HOCl}$ chemistry is understood on a global scale, MIPAS climatologies are compared to model calculations of the Chemistry Climate Model (CCM) EMAC (ECHAM5/MESSy Atmospheric Chemistry model) (Jöckel et al., 2006). EMAC has been developed at the Max-Planck-Institute for Chemistry in Mainz and is a combination of the general circulation model ECHAM5 (Roeckner et al., 2006) and different submodels such as the chemistry submodel MECCA1 (Sander et al., 2005) combined through the Modular Earth Submodel System MESSy (Jöckel et al., 2005).

For this study data from a simulation from 1994 to 2011 with EMAC Version 1.10 are used. The simulation was performed with horizontal resolution T42 $\left(2.8^{\circ} \times 2.8^{\circ}\right)$ and with 39 layers, covering the atmosphere from the surface up to $0.01 \mathrm{hPa}(\approx 80 \mathrm{~km})$. A Newtonian relaxation technique of the prognostic variables surface pressure and temperature, vorticity and divergence above the boundary layer and below $10 \mathrm{hPa}$ towards ECMWF operational analysis data has been applied, in order to nudge the model dynamics towards the observed meteorology. The boundary conditions for greenhouse gases are from the IPCC-A1B scenario (IPCC, 2001) adapted to observations from the AGAGE database (Prinn et al., 2001) and for halogenated hydrocarbons from the WMO-Ab scenario (World Meteorological Organization, 2007).

The simulation includes a comprehensive atmospheric chemistry setup for the troposphere, the stratosphere and the lower mesosphere. Reaction rate constants and photochemical data follow in general the JPL-2002 recommendations (Sander et al., 2003) except for $\mathrm{HO}_{2}+\mathrm{ClO} \longrightarrow \mathrm{HOCl}+\mathrm{O}_{2}$ for which JPL-2009 (Sander et al., 2010) is used. Additional sensitivity calculations were performed where the rate constant for the latter reaction was changed according to JPL2006 (Sander et al., 2006) or Stimpfle et al. (1979) (this particular rate constant did not change from JPL-2002 to JPL2006). The applied submodels are the same as in the simulations in Kirner (2008). In particular we used a new parameterisation of polar stratospheric clouds based on the efficient growth and sedimentation of NAT-particles in the submodel PSC (Kirner et al., 2011).

Monthly mean modeled $\mathrm{HOCl}$ fields, sampled at the respective local time (10:00 a.m./10:00 p.m.) are smoothed by the MIPAS averaging kernels and presented for comparison.

\section{Twenty-two months of HOCl observations}

\subsection{Climatology}

MIPAS HOCl observations are available from June 2002 to March 2004. The typical features are: The pressure level of maximum mixing ratio varies between 6 and $2 \mathrm{hPa}$ 
(approx. 35-43 km, respectively). Largest mixing ratios occasionally exceed $200 \mathrm{ppt}$. The altitude of largest mixing ratios is generally lower in the summer hemisphere than in the winter hemisphere (Fig. 2), except sometimes for polar vortices. This feature is in tendency also reproduced by the model calculations. The $\mathrm{HOCl}$ equilibrium concentration depends on its photolysis rate, temperature, and, among others, on the concentrations of $\mathrm{HO}_{2}, \mathrm{ClO}$, and $\mathrm{OH}$, which have altitude-dependent diurnal and annual cycles in themselves (Brasseur and Solomon, 2005), leading, as a net effect, to the observed behaviour. Further, mixing ratios are in general higher in the summer hemisphere than in the winter hemisphere, and maximal mixing ratios are found in the lower midlatitudes of the summer hemisphere. These maxima coincide with those of $\mathrm{ClO}$, which is also measured by MIPAS (Glatthor et al., 2004). This suggests that the latitudinal $\mathrm{HOCl}$ distribution is largely driven by the availability of $\mathrm{ClO}$. Both the altitude of the maximum as well as its latitude are well reproduced by the model. Also the modeled and measured mixing ratios agree reasonably well at most latitudes and altitudes, if the rate constant for $\mathrm{HO}_{2}+\mathrm{ClO}$ $\longrightarrow \mathrm{HOCl}+\mathrm{O}_{2}$ from the JPL-2009 recommendation (Sander et al., 2010) is used. The use of the rate constant from the JPL-2006 recommendation (Sander et al., 2006) leads to $\mathrm{HOCl}$ mixing ratios underestimated by about $40 \%$, while rate constants suggested by Stimpfle et al. (1979) produce too high $\mathrm{HOCl}$ mixing ratios (second and third panel in Fig. 3). Some residuals, particularly in the Northern hemisphere, still persist: even with rate constants from the most recent recommentation (JPL-2009) HOCl amounts are underestimated particularly in the midlatitude summer maximum and overestimated in the polar winter upper stratosphere.

When EMAC is run in its default mode, stratospheric $\mathrm{HOCl}$ concentrations are largely overestimated during polar night conditions (bottom panel in Fig. 3). This is because EMAC uses by default a family approach for $\mathrm{HOCl}$ and other comparatively short-lived chlorine species for transport modelling, probably because in this mode the model better satisfies the conservation of mass; this means that after the integration of chemical changes, which is calculated explicitly for each species, transport is calculated for the related family. Afterwards, the partitioning is re-adjusted according to the partitioning before the transport time step. This leads to artefacts particularly if air is transported from the illuminated part of the vortex into the dark part. Re-partitioning as described above then represents an airmas which has always been in the dark while it actually had been illuminated before. To obtain realistic results, it is important to simulate $\mathrm{HOCl}$ explicitly rather than as a member of a family. The model calculations presented in this paper are based on explicit modeling of both the chemistry and the transport of $\mathrm{HOCl}$.

During nighttime the maximum of the $\mathrm{HCl}$ mixing ratio is found at higher altitudes than during daytime (Fig. 4). The approximate altitude (ca. $39 \mathrm{~km}$ or $3 \mathrm{hPa}$ during nighttime)
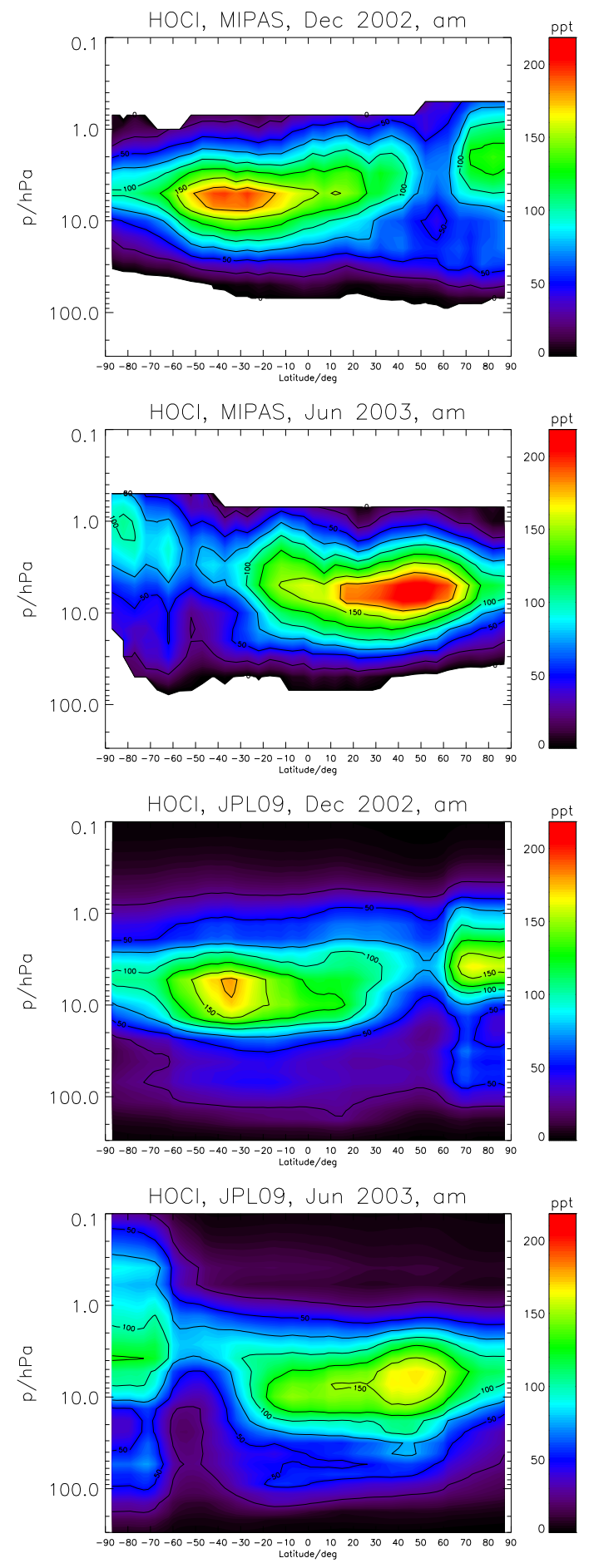

Fig. 2. Zonal mean $\mathrm{HOCl}$ distribution in December 2002 (top panel) and June 2003 (second panel). Measurements taken during the descending part of the orbit, i.e. morning measurements, are shown. The maximum mixing ratios are found in the summer hemisphere. White areas represent altitudes where MIPAS was not sensitive to $\mathrm{HOCl}$. The lower panels represent the respective model calculations, after application of MIPAS averaging kernels. 

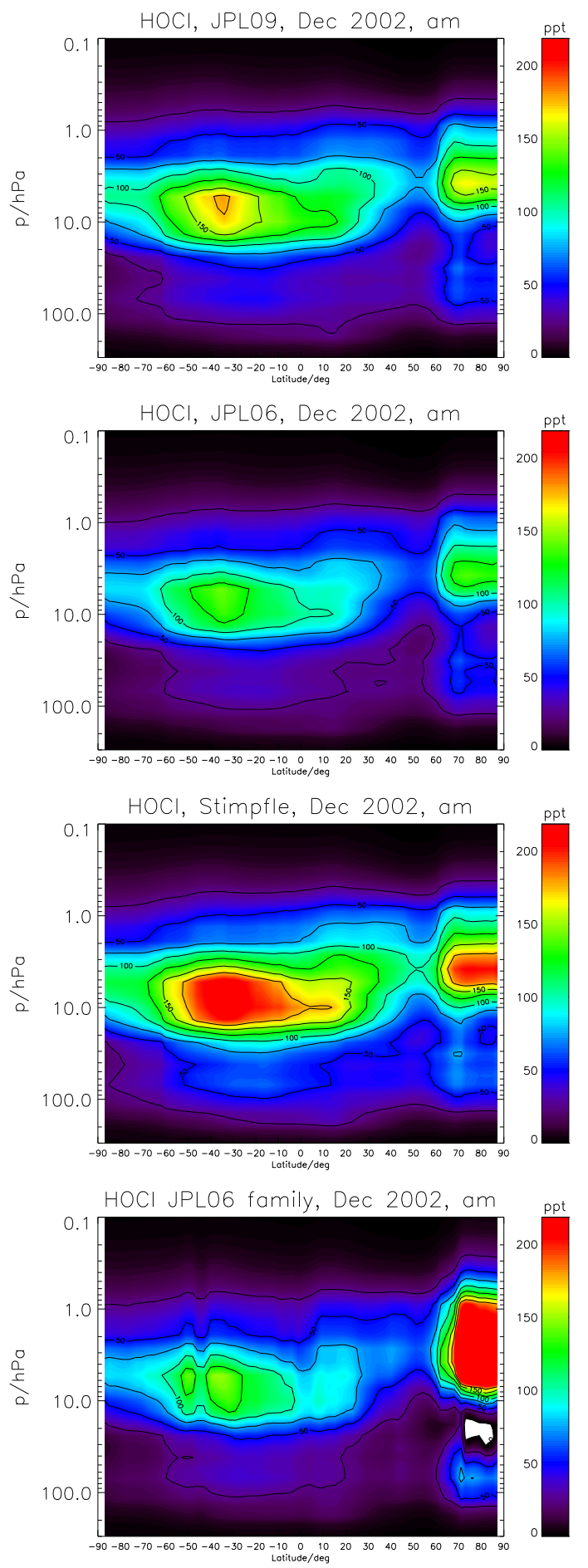

Fig. 3. Modeled mean $\mathrm{HOCl}$ distributions in December 2002 for different model setups: top three panels: explicit $\mathrm{HOCl}$ modeling and rate constants from JPL-2009, JPL-2006, and Stimpfle et al. (1979) (top to bottom); lowermost panel: EMAC in its default mode with family approach for $\mathrm{HOCl}$ and $\mathrm{HOCl}$ formation rate constant from JPL-2006. White areas in the model fields represent negative data caused by side wiggles of MIPAS averaging kernels.
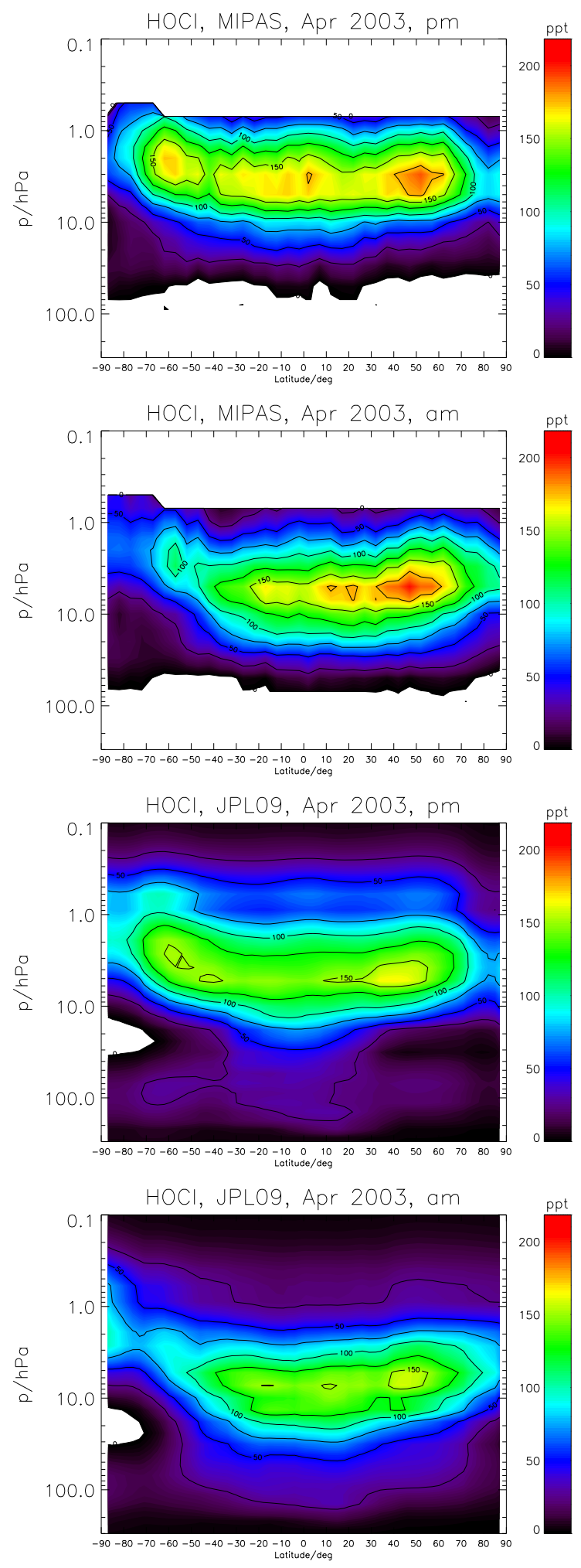

Fig. 4. MIPAS zonal mean $\mathrm{HOCl}$ distribution in April 2003 at 10:00 p.m. (top panel) and 10:00 a.m. (second panel), and respective model calculations (third and fourth panel). 


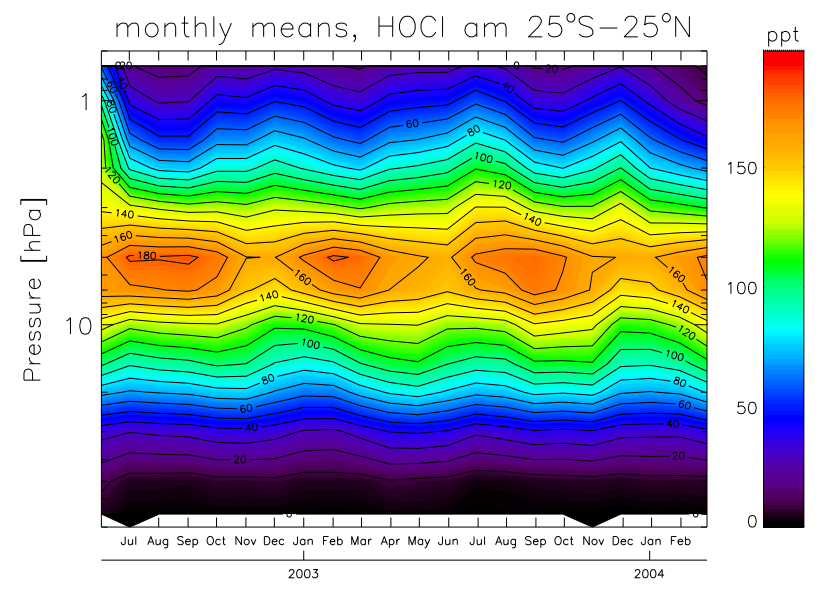

Fig. 5. Timeseries of $\mathrm{HOCl}$ zonal mean molar mixing ratios for the equatorial region $25^{\circ} \mathrm{S}-25^{\circ} \mathrm{N}$. Measurements of the descending part of the orbit (10:00 a.m.) are shown.

and the altitude difference between the nighttime and the daytime maximum of about $5 \mathrm{~km}$ are consistent with the profiles and their diurnal variation found by Chance et al. (1989, 1996) who measured $\mathrm{HOCl}$ in the far infrared spectral region from a balloon-borne platform. This shift in altitude of the maximum seems to be more pronounced at lower latitudes than at higher latitudes, leading to quite a flat distribution of the peak altitude over latitude during nighttime contrasting to a slightly more banana-shaped distribution during daytime. Again, this behaviour is the net effect of several interacting processes depending on the concentrations of $\mathrm{HO}_{2}$ and $\mathrm{ClO}$ and on photolysis rates, which all have their own altitudedependent diurnal cycle. No such diurnal variation of the altitude of maximal mixing ratios is observed in $\mathrm{ClO}$, which suggests that this effect is driven by the eqilibrium of $\mathrm{HO}_{2}$ dependent production and loss through photolysis. Both the altitude of the $\mathrm{HOCl}$ maximum and the amount are slightly underestimated by EMAC, but the general tendency of nighttime enhancement in higher and daytime enhancement in lower altitudes is reproduced.

The representation of the data as a timeseries (Fig. 5) for tropical latitudes (equatorward of $\pm 25^{\circ}$ ) shows a semiannual oscillation of the peak mixing ratios with an amplitude of about 30 ppt. Largest abundances are found in July/August and in January/February, i.e. during northern and southern summer when local noon solar elevation is lowest at equatorial latitudes. At equinox the peak mixing ratios start to decrease to reach their minimum at solstice.

In Fig. 6 the $\mathrm{HOCl}$ distribution of December 2003 is shown for both a.m. and p.m. measurements. The December 2003 monthly mean is dominated by measurements when the Northern polar vortex was still intact throughout all stratospheric altitudes, although a major warming happened in early January 2004, starting with a break-up of the vortex in the upper stratosphere in late December (Manney et al.,
2005). Particular low $\mathrm{HOCl}$ mixing ratios (occasionally below $80 \mathrm{ppt}$ at the maximum) are found during daytime in early winter higher midlatitudes. During nighttime this minimum disappears, suggesting that photochemical loss during daytime is no longer compensated by insolation-dependent production. This daytime minimum is surrounded by regions of more abundant $\mathrm{HOCl}$. $\mathrm{HOCl}$ shows a maximum at lower mid-latitudes of the summer hemisphere and decreases towards high latitudes of both hemispheres, reflecting the decrease of the $\mathrm{HOCl}$ sources $\mathrm{ClO}$ and $\mathrm{HO}_{2}$. At polar night, $\mathrm{HOCl}$ is enhanced due to the absence of $\mathrm{HOCl}$ loss. This leads to an $\mathrm{HOCl}$ minimum just outside of the polar night. The subpolar $\mathrm{HOCl}$ daytime minimum is also observed in Southern winter (Fig. 2, second panel).

The polar winter $\mathrm{HOCl}$ maximum is not exactly centered at the pole but slightly offset, forming a weakly pronounced minimum in the very inner part of the vortex over the pole where due to darkness no $\mathrm{HO}_{\mathrm{x}}$ chemistry is happening. This secondary minimum is more pronounced in the modeled distributions than in the measurements; it is, however, visible in the southern polar vortex June 2003 measurements (Fig. 2, second panel). The polar winter $\mathrm{HOCl}$ distribution is in general well reproduced by the model in a qualitative sense but modeled mixing ratios are somewhat too high.

A separated $\mathrm{HOCl}$ maximum is seen in the lower polar winter stratosphere around $50-10 \mathrm{hPa}$. This feature has first been observed by von Clarmann et al. (2009a) in the Antarctic winter of 2002 but is now seen in all polar winters for which MIPAS HOCl measurements are available (Figs. 7 and 8). This feature is in tendency reproduced by the model but to a much lesser extent (Fig. 7). This maximum has been attributed to heterogeneous chemistry, presumably to heterogeneous $\mathrm{ClO}$ formation preceding gas-phase $\mathrm{HOCl}$ formation. The fact that this feature is more pronounced in southern polar winters is quite plausible and supports the hypothesis of being linked to heterogeneous chemistry, because it is well known that chlorine activation through heterogeneous chemistry is much more frequent and efficient in southern polar vortices. Austral winter chlorine activation from May until September 2002 onward has been reported by Feng et al. (2005). Very early chlorine activation was reported for the northern winter 2002/2003 by Tilmes et al. (2003), both in consistence with our $\mathrm{HOCl}$ observations. Since generation of $\mathrm{HOCl}$ via reaction of $\mathrm{HO}_{2}$ with $\mathrm{ClO}$ depends on $\mathrm{HO}_{\mathrm{x}}$ chemistry and thus on availability of sunlight, this $\mathrm{HOCl}$ maximum is not centered at the pole.

Figure 8 shows the temporal development of polar $\mathrm{HOCl}$ mixing ratios. Both the upper $(3 \mathrm{hPa})$ and lower $(20 \mathrm{hPa})$ polar winter maxima are clearly seen, as well as the illumination-dependent varying altitude of the maximum from local spring to fall.

Standard deviations of the monthly zonal means are normally in the range of 50 to $80 \mathrm{ppt}$ in the altitude of the mixing ratio maximum. Comparison to the estimated single 

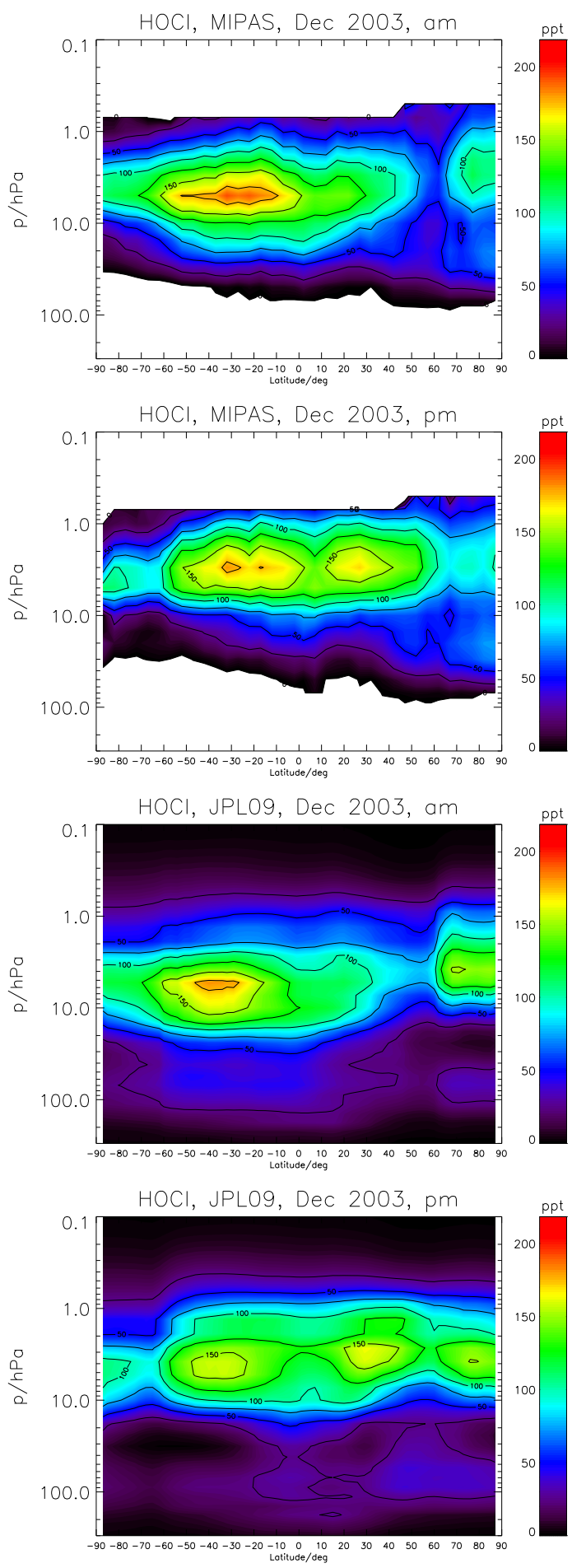

Fig. 6. Zonal mean morning (top panel) and evening (second panel) $\mathrm{HOCl}$ distribution in Arctic winters (December 2003). Note low values in sub-polar regions. The third and fourth panel represent the respective model data sets.
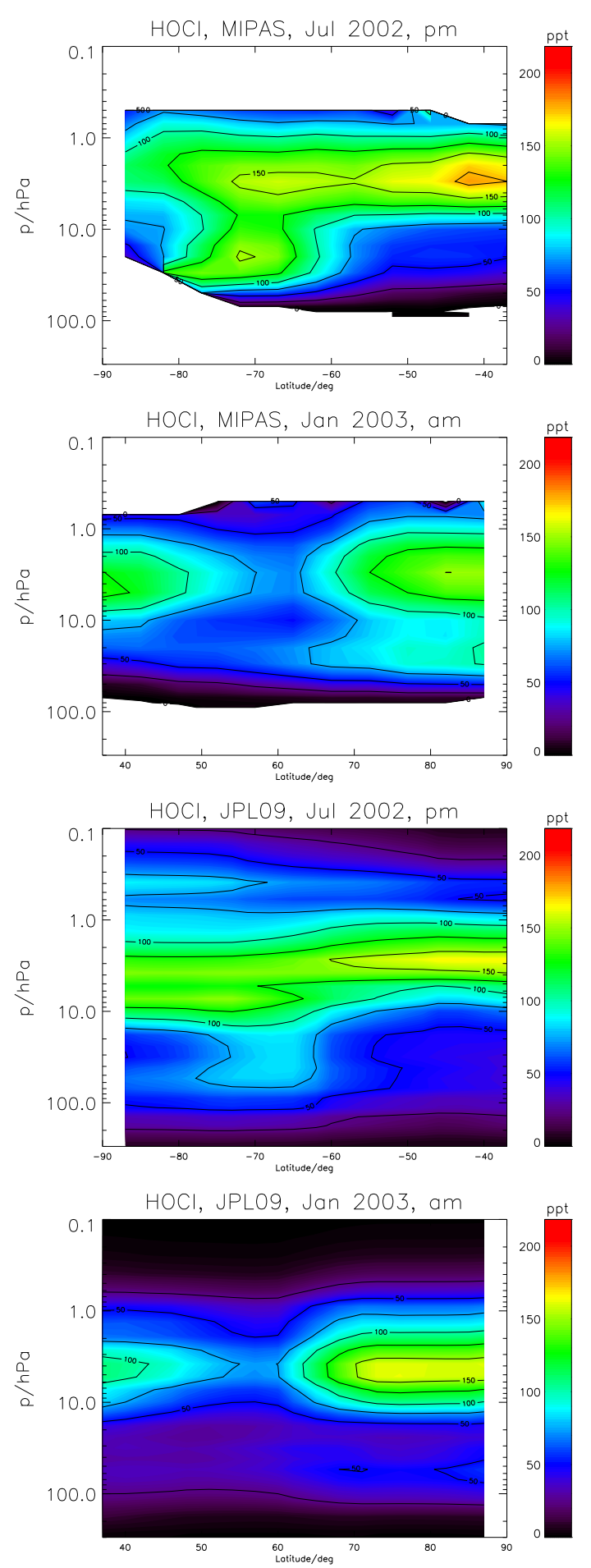

Fig. 7. Increased $\mathrm{HOCl}$ amounts in the southern (July 2002, evening, upper panel) and northern (January 2003, morning, second panel) polar winter stratospheric vortex subsequent to chlorine activation, together with related model calculations (third and fourth panel). Note that in the polar night the time of the day is of no concern. 

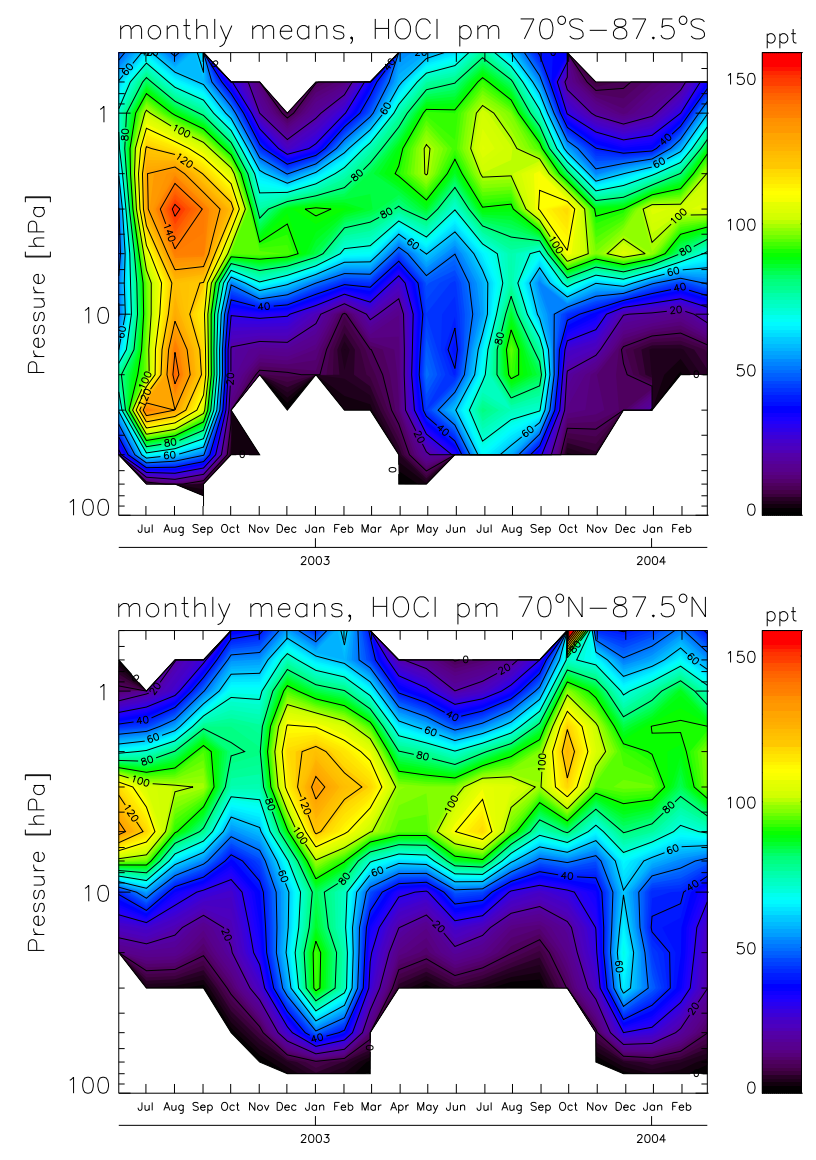

Fig. 8. Timeseries of $\mathrm{HOCl}$ zonal mean molar mixing ratios poleward of $70^{\circ}$ for the Antarctic (upper panel) and the Arctic (lower panel). Measurements of the ascending part of the orbit are shown.

profile error (approx. 40 ppt) suggests that the variability within a month and latitude bin is about 30 to 70 ppt. Under polar night conditions standard deviations often reach $150 \mathrm{ppt}$, reflecting displaced or inhomogeneously composed polar vortices or rapid composition changes within the averaging period.

The complete set of plots of MIPAS $\mathrm{HOCl}$ climatologies is available as Supplement from July 2002 to March 2004, and the data files in netcdf format will be made available via SPARC.

\subsection{Particular events}

During the observation period there were two very special events, which are scientifically interesting but require a caveat with respect to the climatological representativeness of the MIPAS data set. These are the split of the Antarctic polar vortex in the Austral winter of 2002, and the solar proton event around Halloween in 2003.

\subsubsection{The split vortex event in 2002}

The split vortex event in 2002 was characterized by a major warming (Allen et al., 2003; Sinnhuber et al., 2003; Krüger et al., 2005; Charlton et al., 2005) going along with pronounced wave activity involving planetary waves of wavenumber 1 to 3 (Wang et al., 2005; Newman and Nash, 2005) which led to a displacement, distortion, and finally a split of the polar vortex. While the lower stratospheric maximum of $\mathrm{HOCl}$ has been attributed to heterogeneous chemistry, large $\mathrm{HOCl}$ amounts near $4 \mathrm{hPa}$ have been attributed to exposure of $\mathrm{Cl}_{\mathrm{y}}$-rich polar vortex air to sunlight due to vortex displacement, triggering $\mathrm{HO}_{\mathrm{x}}$ chemistry (von Clarmann et al., 2009a). Indeed, such large $\mathrm{HOCl}$ amounts were not observed in the Antarctic winter of 2003 (Fig. 9). The southern polar winter $2002 \mathrm{HOCl}$ distributions resemble rather those of the northern winters within the observation period, where high $\mathrm{HOCl}$ concentrations at around $2 \mathrm{hPa}$ seem to be the rule rather than the exception (c.f. Fig. 2 for comparison). This behaviour is not unexpected since due to larger northern hemispheric wave activity the polar vortex there is often displaced, distorted, and thus exposed to sunlight.

\subsubsection{The Halloween solar storm in 2003}

The Halloween solar proton event (SPE) in 2003 was one of the largest in the past fourty years (Degenstein et al., 2005) and resulted in ozone depletion subsequent to $\mathrm{HO}_{\mathrm{x}}, \mathrm{NO}_{\mathrm{x}}$, $\mathrm{NO}_{\mathrm{y}}$ and chlorine chemistry perturbations (Jackman et al., 2005; López-Puertas et al., 2005a,b; Jackman et al., 2008; Verronen et al., 2008). Observations of $\mathrm{HOCl}$ enhancements in response to the solar proton event gave evidence of perturbed chlorine chemistry as well as the first experimental evidence of perturbed $\mathrm{HO}_{\mathrm{x}}$ chemistry (von Clarmann et al., 2005). These $\mathrm{HO}_{x}$ perturbations were later confirmed by direct hydroxyl observations (Verronen et al., 2006). Within the context of this climatological analysis it is important to note that $\mathrm{HOCl}$ measurements in October and November 2003 might not be representative for this season, although the observed $\mathrm{HOCl}$ enhancements were very localized and lasted only a few days and thus are not resolved in the monthly zonal means.

\section{Conclusions}

The first global measurements covering nearly two annual cycles of stratospheric $\mathrm{HOCl}$ are presented. The most important features are (a) a mixing ratio maximum in summer midlatitudes at about $5 \mathrm{hPa}$; (b) an increase of the altitude of maximum mixing ratios during nighttime; (c) a minimum in winter high midlatitudes; (d) occasional enhancements in polar vortices, both in the altitude regimes of gasphase and of heterogeneous chemistry. The observed features are generally well reproduced by the model calculations, which have been considerably improved by the most 

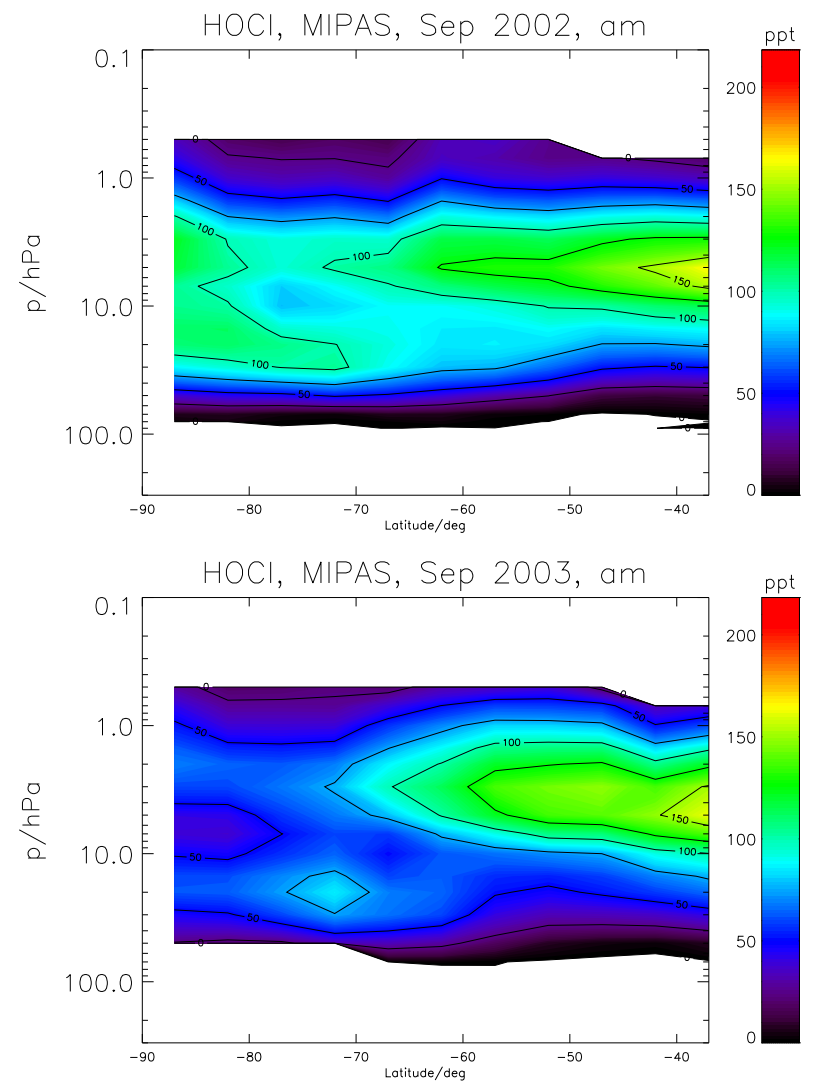

Fig. 9. Large $\mathrm{HOCl}$ amounts in the upper southern polar vortex are found in the southern winter 2002 (upper panel) when unusual planetary wave activity led to displacement, deformation, and split of the polar vortex, but not in 2003 (lower panel) when the polar vortex behaved normally. HOCl September zonal mean values of the descending part of the orbit, i.e. morning measurements, are shown.

recent update of the recommendation of chemical kinetics data by Sander et al. (2010). Some differences, however, remain: Modeled $\mathrm{HOCl}$ mixing ratios are still too low except in the polar winter stratosphere, where $\mathrm{HOCl}$ amounts are overestimated by the model. Large discrepancies between measurements and EMAC operated in its default mode in the mid-stratosphere during polar night could be traced back to the family approach used for $\mathrm{HOCl}$ transport.

The question to which extent this dataset is representative in a climatological sense or if it is dominated by particular atmospheric situations of the measurement period will be answered by a multi-instrument climatology involving also MLS and JEM/SMILES HOCl measurements.

\section{Appendix A}

\section{Interpolation of standard deviation and number of measurements}

Let $x_{1} \ldots x_{m}$ be the measurements in latitude bin 1 , and $y_{1} \ldots y_{n}$ the measurements in latitude bin 2. Zonal means $\bar{x}$ and $\bar{y}$ in each of these bins are

$\bar{x}=\frac{\sum_{i=1}^{m} x_{i}}{m}$
$\bar{y}=\frac{\sum_{j=1}^{n} y_{i}}{n}$.

Weighting by the inverse estimated error variances of the single measurements is intentionally not performed as to avoid biases due to atmospheric state dependent precision. For example, the MIPAS retrieval error is generally larger in a colder atmosphere, thus measurements in warmer parts of the atmosphere would be overrepresented. The standard deviation of the samples are

$\sigma_{x}=\sqrt{\frac{\sum_{i=1}^{m}\left(x_{i}-\bar{x}\right)^{2}}{m-1}}$

$\sigma_{y}=\sqrt{\frac{\sum_{j=1}^{n}\left(y_{j}-\bar{y}\right)^{2}}{n-1}}$.

The interpolation to the desired latitude is

$\bar{z}=(v, w)\left(\begin{array}{l}\bar{x} \\ \bar{y}\end{array}\right)=v \bar{x}+w \bar{y}$

where $v$ and $w$ are weighting factors depending on the distances between the initial mean measurement geolocations $l_{x}$ and $l_{y}$ and the geolocation of the interpolated measurement $l_{z}$ :

$$
\begin{aligned}
v & =\frac{l_{z}-l_{y}}{l_{x}-l_{y}}=1-\frac{l_{x}-l_{z}}{l_{x}-l_{y}} \\
w & =1-v
\end{aligned}
$$

The standard deviation $\sigma_{z}$ of the interpolated mixing ratio is, according to generalized Gaussian error estimation

$$
\begin{aligned}
& \sigma_{z}=\sqrt{(v, w)\left(\begin{array}{cc}
\sigma_{x}^{2} & r \\
\sigma_{x} \sigma_{y} \\
r \sigma_{x} \sigma_{y} & \sigma_{y}^{2}
\end{array}\right)\left(\begin{array}{c}
v \\
w
\end{array}\right)} \\
& =\sqrt{v^{2} \sigma_{x}^{2}+2 v w r \sigma_{x} \sigma_{y}+w^{2} \sigma_{y}^{2}} .
\end{aligned}
$$

For fully correlated $x$ and $y$ this reduces to simple linear interpolation of the standard deviation while for fully independent $x$ and $y$ this reduces to quadratic interpolation of variances. It is important to note, that interpolation of covariance 
matrices from a coarser to a finer grid does not represent fine-scale variability which does not show up in the coarse grid. This caveat, however, does not apply to the application of this paper, because the target latitude grid is coarser than the initial one on which the MIPAS measurements were performed.

\section{The virtual number of measurements}

The data format of the SPARC Data Initiative also requires the number of measurements $k$ used to calculate the zonal mean. Also this quantity is not trivial to interpolate. We argue that the purpose of this quantity is that the user can calculate the standard error of the mean, $\sigma_{\text {stderr. }}$. The usual recipe for this purpose assumes independent data and is

$\sigma_{\text {stderr }}=\frac{\sigma}{\sqrt{k}}$.

We argue that the most useful estimate of the number of observations is that where Eq. (A6) holds, regardless how the standard deviation $\sigma$ was obtained. We thus define a "virtual number of measurements", $k_{\mathrm{v}}$ which is defined as

$k_{\mathrm{v}}=\sigma^{2} / \sigma_{\text {stderr }}^{2}$

The direct estimate of the interpolated zonal mean $z$ from the single measurements $x_{i}$ and $y_{j}$ is (averaging and interpolation in one step)

$$
z=\left(\frac{v_{1}}{m} \ldots \frac{v_{m}}{m} ; \frac{w_{1}}{n} \ldots \frac{w_{n}}{n}\right)\left(\begin{array}{c}
x_{1} \\
\vdots \\
x_{m} \\
y_{1} \\
\vdots \\
y_{m}
\end{array}\right)=\boldsymbol{g}^{T}\left(\begin{array}{c}
x_{1} \\
\vdots \\
x_{m} \\
y_{1} \\
\vdots \\
y_{m}
\end{array}\right)
$$

The standard error of $z$ is calculated by generalized Gaussian error propagation. We assume $m \leq n$ to allow for additional measurements in one bin without counterpart in the other bin). We further assume zero correlation between multiple measurements within one latitude bin; this approximation is justified because these measurements belong mostly to different orbits, and with MIPAS it takes about three days until the same geolocation is observed again. In contrast, correlations beween subsequent measurements of the same orbit but different latitude bins are considered, because these measurements are only $70 \mathrm{~s}$ and $510 \mathrm{~km}$ apart.

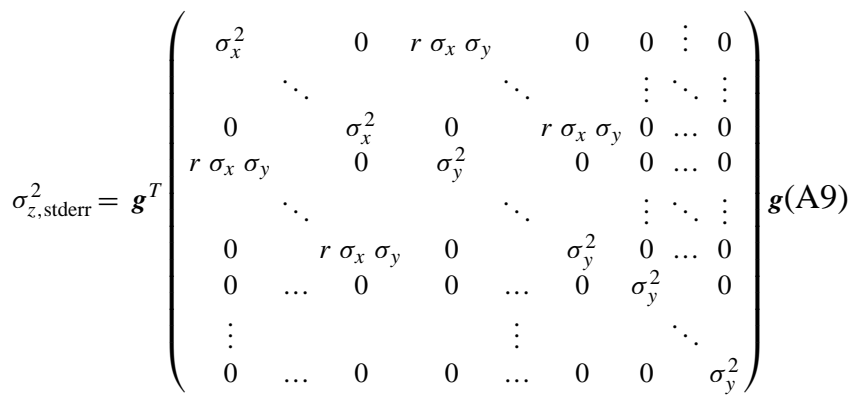

$=\sum_{i=1}^{m} \frac{v^{2} \sigma_{x}^{2}}{m^{2}}+\sum_{j=1}^{n} \frac{w^{2} \sigma_{y}^{2}}{n^{2}}+2 \sum_{i=1}^{m} \frac{r v w \sigma_{x} \sigma_{y}}{m}$

With $\sigma_{z}$ obtained from Eq. (A5) and $\sigma_{z \text {,stderr }}^{2}$ obtained from Eq. (A9), the virtual number of measurements $k_{\mathrm{v}}$ can be calculated using Eq. (A7). Althouh the result can be a fraction, in order not to confuse the user and to comply with the data format of the SPARC Data Initiative, we round the result to the nearest lower integer.

\section{Estimation of the correlation coefficient}

Ideally the correlation coefficient $r$ can be calculated in a straight forward manner along with the zonal means and their standard deviations. However, the given data structure may me obstructive for this purpose. We thus propose a scheme to estimate $r$ without going back to the single measurements. We assume that the total observed variability $\sigma_{\text {observed }}$ (e.g. $\sigma_{x}$ or $\sigma_{y}$ ) is composed of measurement error $\sigma_{\text {noise }}$ and natural variability $\sigma_{\text {nat }}$ as

$\sigma_{\text {observed }}^{2}=\sigma_{\text {noise }}^{2}+\sigma_{\text {nat }}^{2}$

Measurement errors are in good approximation uncorrelated between subsequent measurements $\left(r_{\text {noise }}=0\right)$ while natural variations are supposed to be highly correlated $\left(r_{\text {nat }} \approx 1\right)$ between subsequent measurements. We infer $r$ by decomposing each value in a true component ( $x_{i, \text { true }}$ and $y_{i, \text { true }}$, respectively) and a noise term $\left(\epsilon_{i}\right.$ and $\gamma_{i}$, respectively):

$$
\begin{aligned}
r= & \frac{\sum_{i=1}^{m}\left(x_{i}-\bar{x}\right)\left(y_{i}-\bar{y}\right)}{(m-1) \sigma_{x} \sigma_{y}} \\
= & \frac{\sum_{i=1}^{m}\left(x_{i, \text { true }}-\bar{x}\right)\left(y_{i, \text { true }}-\bar{y}\right)}{(m-1) \sigma_{x} \sigma_{y}}+\frac{\sum_{i=1}^{m}\left(x_{i, \text { true }}-\bar{x}\right) \gamma_{i}}{(m-1) \sigma_{x} \sigma_{y}}+ \\
& \frac{\sum_{i=1}^{m}\left(y_{i, \text { true }}-\bar{y}\right) \epsilon_{i}}{(m-1) \sigma_{x} \sigma_{y}}+\frac{\sum_{i=1}^{m} \epsilon_{i} \gamma_{i}}{(m-1) \sigma_{x} \sigma_{y}},
\end{aligned}
$$

where the latter three terms are ignored because the noise terms are assumed to be uncorrelated and thus to have a tendency to cancel out. With

$a=\frac{\sigma_{x, \text { nat }}}{\sigma_{x}}$

and

$b=\frac{\sigma_{y, \text { nat }}}{\sigma_{y}}$

we can rewrite the surviving term of Eq. (A11) as

$$
\begin{array}{r}
r=a b \frac{\sum_{i=1}^{m}\left(x_{i, \text { true }}-\bar{x}\right)\left(y_{i, \text { true }}-\bar{y}\right)}{(m-1) \sigma_{x} \sigma_{y}} \\
=a b \frac{\sqrt{\sigma_{x}^{2}-\sigma_{x, \text { noise }}^{2}} \sqrt{\sigma_{y}^{2}-\sigma_{y, \text { noise }}^{2}}}{\sigma_{x} \sigma_{y}}
\end{array}
$$


Since both the observed standard deviations $\sigma_{x}$ and $\sigma_{y}$ and error estimates $\sigma_{x \text {,noise }}$ and $\sigma_{x \text {,noise }}$ are available for MIPAS retrievals, we can estimate $r$ without retrieving information which pairs of measurements $x_{i}$ and $y_{i}$ belong together.

\section{Supplementary material related to this article is available online at: http://www.atmos-chem-phys.net/12/1965/2012/ acp-12-1965-2012-supplement.zip.}

Acknowledgements. The retrievals of IMK/IAA were performed on the HP XC4000 of the Scientific Supercomputing Center (SSC) Karlsruhe under project grant MIPAS. IMK data analysis was supported by DLR under contract number 50EE0901. BF was supported by the Spanish project AYA200803498/ESP by the project 200950I081 of CSIC. MIPAS level 1B data were provided by ESA. We acknowledge support by Deutsche Forschungsgemeinschaft and Open Access Publishing Fund of Karlsruhe Institute of Technology.

Edited by: T. Röckmann

\section{References}

Abbatt, J. P. D. and Molina, M. J.: The Heterogeneous Reaction $\mathrm{HOCl}+\mathrm{HCl} \rightarrow \mathrm{Cl}_{2}+\mathrm{H}_{2} \mathrm{O}$ on ice and nitric acid trihydrate: Reaction probabilities and stratospheric implications, Geophys. Res. Lett., 19, 461-464, doi:10.1029/92GL00373, 1992.

Allen, D. R., Bevilacqua, R. M., Nedoluha, G. E., Randall, C. E., and Manney, G. L.: Unusual stratospheric transport and mixing during the 2002 Antarctic winter, Geophys. Res. Lett., 30, 1599, doi:10.1029/2003GL017117, 2003.

Baron, P., Urban, J., Sagawa, H., Möller, Murtagh, D. P., Mendrok, J., Dupuy, E., Sato, T. O., Ochiai, S., Suzuki, K., Manabe, T., Nishibori, T., Kikuchi, K., Sato, R., Takayanagi, M., Murayama, Y., Shiotani, M., and Kasai, Y.: The Level 2 research product algorithms for the Superconducting Submillimeter-Wave LimbEmission Sounder (SMILES), Atmos. Meas. Tech., 4, 21052124, doi:10.5194/amt-4-2105-2011, 2011.

Brasseur, G. and Solomon, S.: Aeronomy of the Middle Atmosphere- Chemistry and Physics of the Stratosphere and Mesosphere, Springer, P.O.Box 17, 3300 AA Dordrecht, The Netherlands, 2005.

Chance, K. V., Johnson, D. G., and Traub, W. A.: Measurement of stratospheric HOCl: Concentration profiles, including diurnal variation, J. Geophys. Res., 94, 11059-11069, 1989.

Chance, K., Traub, W. A., Johnson, D. G., Jucks, K. W., Ciarpallini, P., Stachnik, R. A., Salawitch, R. J., and Michelsen, H. A.: Simultaneous measurements of stratospheric $\mathrm{HO}_{\mathrm{X}}, \mathrm{NO}_{\mathrm{X}}$ and $\mathrm{Cl}_{\mathrm{X}}$; Comparison with a photochemical model, J. Geophys. Res., 101, 9031-9043, 1996.

Charlton, A. J., O’Neill, A., Lahoz, W. A., and Berrisford, P.: The splitting of the stratospheric polar vortex in the southern hemisphere, September 2002: Dynamical evolution, J. Atmos. Sci., 62, 590-602, 2005.
Chauhan, S., Höpfner, M., Stiller, G. P., von Clarmann, T., Funke, B., Glatthor, N., Grabowski, U., Linden, A., Kellmann, S., Milz, M., Steck, T., Fischer, H., Froidevaux, L., Lambert, A., Santee, M. L., Schwartz, M., Read, W. G., and Livesey, N. J.: MIPAS reduced spectral resolution UTLS-1 mode measurements of temperature, $\mathrm{O}_{3}, \mathrm{HNO}_{3}, \mathrm{~N}_{2} \mathrm{O}, \mathrm{H}_{2} \mathrm{O}$ and relative humidity over ice: retrievals and comparison to MLS, Atmos. Meas. Tech., 2, 337 353, doi:10.5194/amt-2-337-2009, 2009.

Cofield, R. E. and Stek, P. C.: Design and field-of-view calibration of 114-660 GHz optics of the Earth Observing System Microwave Limb Sounder, IEEE T. Geosci. Remote, 44, 11661181, 2006.

Crutzen, P. J., Müller, R., Brühl, C., and Peter, T.: On The Potential Importance of the Gase Phase Reaction $\mathrm{CH}_{3} \mathrm{O}_{2}+\mathrm{ClO} \rightarrow \mathrm{ClOO}+\mathrm{CH}_{3} \mathrm{O}$ and the Heterogeneous Reaction $\mathrm{HOCl}+\mathrm{HCl} \rightarrow \mathrm{H}_{2} \mathrm{O}+\mathrm{Cl}_{2}$ in "Ozone Hole" Chemistry, Geophys. Res. Lett., 19, 1113-1116, 1992.

Daniel, J. S., Solomon, S., Portmann, R. W., and Garcia, R. R.: Stratospheric ozone destruction: The importance of bromine relative to chlorine, J. Geophys. Res. 104, 23871-23880O, 1999.

Degenstein, D. A., Lloyd, N. D., Bourassa, A. E., Gattinger, R. L., and Llewellyn, E. J.: Observations of mesospheric ozone depletion during the October 28, 2003 solar proton event by OSIRIS, Geophys. Res. Lett., 32, L03S11, doi:10.1029/2004GL021521, 2005.

Feng, W., Chipperfield, M. P., Roscoe, H. K., Remedios, J. J., Waterfall, A. M., Stiller, G. P., Glatthor, N., Höpfner, M., and Wang, D.-Y.: Three-dimensional Model Study of the Antarctic Ozone Hole in 2002 and Comparison with 2000, J. Atmos. Sci., 62, 822-837, 2005.

Fischer, H., Birk, M., Blom, C., Carli, B., Carlotti, M., von Clarmann, T., Delbouille, L., Dudhia, A., Ehhalt, D., Endemann, M., Flaud, J. M., Gessner, R., Kleinert, A., Koopman, R., Langen, J., López-Puertas, M., Mosner, P., Nett, H., Oelhaf, H., Perron, G., Remedios, J., Ridolfi, M., Stiller, G., and Zander, R.: MIPAS: an instrument for atmospheric and climate research, Atmos. Chem. Phys., 8, 2151-2188, doi:10.5194/acp-8-2151-2008, 2008.

Glatthor, N., von Clarmann, T., Fischer, H., Grabowski, U., Höpfner, M., Kellmann, S., Kiefer, M., Linden, A., Milz, M., Steck, T., Stiller, G. P., Mengistu Tsidu, G., Wang, D. Y. and Funke, B.: Spaceborne $\mathrm{ClO}$ observations by the Michelson Interferometer for Passive Atmospheric Sounding (MIPAS) before and during the Antarctic major warming in September/October 2002, J. Geophys. Res., 109, D11307, doi:10.1029/2003JD004440, 2004.

Hanson, D. R. and Ravishankara, A. R.: Investigation of the reactive and nonreactive processes involving $\mathrm{ClONO}_{2}$ and $\mathrm{HCl}$ on water and nitric acid doped ice, J. Phys. Chem., 96, 2682-2691, 1992.

Hegglin, M. and Tegtmeier, S.: The SPARC Data Initiative, SPARC Newsletter, 36, 22-23, 2011.

IPCC: A contribution of Working Groups I, II and III to the Third Assessment Report of the Integovernmental Panel on Climate Change, in: Climate Change 2001: Synthesis Report, edited by: Watson, R. T. and the Core Writing Team, Cambridge University Press, Cambridge, UK, and New York, USA, 2001.

Jackman, C. H., DeLand, M. T., Labow, G. J., Fleming, E. L., Weisenstein, D. K., Ko, M. K. W., Sinnhuber, M., and Russell, J. M.: Neutral atmospheric influences of the solar proton events in October-November 2003, J. Geophys. Res., 110, A09S27, 
doi:10.1029/2004JA010888, 2005.

Jackman, C. H., Marsh, D. R., Vitt, F. M., Garcia, R. R., Fleming, E. L., Labow, G. J., Randall, C. E., López-Puertas, M., Funke, B., von Clarmann, T., and Stiller, G. P.: Short- and medium-term atmospheric constituent effects of very large solar proton events, Atmos. Chem. Phys., 8, 765-785, doi:10.5194/acp-8-765-2008, 2008.

Jöckel, P., Sander, R., Kerkweg, A., Tost, H., and Lelieveld, J.: Technical Note: The Modular Earth Submodel System (MESSy) - a new approach towards Earth System Modeling, Atmos. Chem. Phys., 5, 433-444, doi:10.5194/acp-5-433-2005, 2005.

Jöckel, P., Tost, H., Pozzer, A., Brühl, C., Buchholz, J., Ganzeveld, L., Hoor, P., Kerkweg, A., Lawrence, M. G., Sander, R., Steil, B., Stiller, G., Tanarhte, M., Taraborrelli, D., van Aardenne, J., and Lelieveld, J.: The atmospheric chemistry general circulation model ECHAM5/MESSy1: consistent simulation of ozone from the surface to the mesosphere, Atmos. Chem. Phys., 6, 50675104, doi:10.5194/acp-6-5067-2006, 2006.

Johnson, D. G., Traub, W. A., Chance, K. V., Jucks, K. W., and Stachnik, R. A.: Estimating the abundance of $\mathrm{ClO}$ from simultaneous remote sensing measurements of $\mathrm{HO}_{2}, \mathrm{OH}$, and $\mathrm{HOCl}$, Geophys. Res. Lett., 22, 1869-1871, 1995.

Kasai, Y. J., Baron, P., Ochiai, S., Mendrok, J., Urban, J., Murtagh, D., Moller, J., Manabe, T., Kikuchi, K., and Nishibori, T.: JEM/SMILES observation capability, in: Sensors, Systems, and Next-Generation Satellites XIII, edited by: Meynart, R., Neeck, S. P., and Shimoda, H., SPIE, 7474, 74740S, doi:10.1117/12.830825, 2009.

Kikuchi, K., Nishibori, T., Ochiai, S., Ozeki, H., Irimajiri, Y., Kasai, Y., Koike, M., Manabe, T.,, Mizukoshi, K., Murayama, Y., Nagahama, T., Sano, T., Sato, R., Seta, M., Takahashi, C., Takayanagi, M., Masuko, H., Inatani, J., Suzuki, M., and Shiotani, M.: Overview and early results of the Superconducting Submillimeter-Wave Limb-Emission Sounder (SMILES), J. Geophys. Res. 115, D23306, doi:10.1029/2010JD014379, 2010.

Kirner, O.: Prozessstudien der stratosphärischen Chemie und Dynamik mit Hilfe des Chemie-Klima-Modells ECHAM5/MESSy1, Ph.D. thesis, Universität Karsruhe, Germany, 2008.

Kirner, O., Ruhnke, R., Buchholz-Dietsch, J., Jöckel, P., Brühl, C., and Steil, B.: Simulation of polar stratospheric clouds in the chemistry-climate-model EMAC via the submodel PSC, Geosci. Model Dev., 4, 169-182, doi:10.5194/gmd-4-169-2011, 2011.

Kovalenko, L. J., Jucks, K. W., Salawitch, R. J., Toon, G. C., Blavier, J.-F., Johnson, D. G., Kleinböhl, A., Livesey, N. J., Margitan, J. J., Pickett, H. M., Santee, M. L., Sen, B., Stachnik, R. A., and Waters, J. W.: Observed and modeled $\mathrm{HOCl}$ profiles in the midlatitude stratosphere: Implication for ozone loss, Geophys. Res. Lett., 34, L19801, doi:10.1029/2007GL031100, 2007.

Krüger, K., Naujokat, B., and Labitzke, K.: The unusual midwinter warming in the Southern hemisphere stratosphere 2002: A comparison to Northern hemisphere phenomena, J. Atmos. Sci., 62, 603-613, 2005.

Larsen, J. C., Rinsland, C. P., Goldman, A., Murcray, D. G., and Murcray, F. J.: Upper limits for stratospheric $\mathrm{H}_{2} \mathrm{O}_{2}$ and $\mathrm{HOCl}$ from high resolution balloon-borne infrared solar absorption spectra, Geophys. Res. Lett., 12, 663-666, 1985.

López-Puertas, M., Funke, B., Gil-López, S., von Clarmann, T., Stiller, G. P., Höpfner, M., Kellmann, S., Fischer, H., and Jack- man, C. H.: Observation of $\mathrm{NO}_{\mathrm{x}}$ enhancement and ozone depletion in the Northern and Southern hemispheres after the OctoberNovember 2003 solar proton Events, J. Geophys. Res., 110, A09S43, doi:10.1029/2005JA011050, 2005a.

López-Puertas, M., Funke, B., Gil-López, S., von Clarmann, T., Stiller, G. P., Höpfner, M., Kellmann, S., Mengistu Tsidu, G., Fischer, H., and Jackman, C. H.: $\mathrm{HNO}_{3}, \mathrm{~N}_{2} \mathrm{O}_{5}$ and $\mathrm{ClONO}_{2}$ Enhancements after the October-November 2003 Solar Proton Events, J. Geophys. Res., 110, A09S44, doi:10.1029/2005JA011051, 2005b.

Manney, G. L., Krüger, K., Sabutis, J. L., Sena, S. A., and Pawson, S.: The remarkable 2003-2004 winter and other recent warm winters in the Arctic stratosphere since the late 1990s, J. Geophys. Res., 110, D04107, doi:10.1029/2004JD005367, 2005.

Millard, G. A., Lee, A. M., and Pyle, J. A.: A model study of the connection between polar and midlatitude ozone loss in the Northern Hemisphere lower stratosphere, J. Geophys. Res., 108, 8323, doi:10.1029/2001JD000899, 2003.

Newman, P. A. and Nash, E. R.: The Unusual Southern Hemisphere Stratosphere Winter of 2002, J. Atmos. Sci., 62, 614-628, 2005.

Prather, M. J.: More rapid polar ozone depletion through the reaction of $\mathrm{HOCl}$ with $\mathrm{HCl}$ on polar stratospheric clouds, Nature, 355, 534-537, 1992.

Prinn, R. G., Huang, J., Weiss, R. F., Cunnold, D. M., Fraser, P. J., Simmonds, P. G., McCulloch, A., Harth, C., Salameh, P., Doherty, S., Wang, R. H. J., Porter, L., and Miller, B. R.: Evidence for substantial variations of atmospheric hydroxyl radicals in the past two decades, Science, 292, 1882-1888, 2001.

Raper, O. F., Farmer, C. B., Zander, R., and Park, J. H.: Infrared Spectroscopic Measurements of Halogenated Sink and Reservoir Gases in the Stratosphere With the ATMOS Instrument, J. Geophys. Res., 92, 9851-9858, 1987.

Roeckner, E., Brokopf, R., Esch, M., Giorgetta, M., Hagemann, S., Koernblueh, L., Manzini, E., Schlese, U., and Schulzweida, U.: Sensitivity of simulated climate to horizontal and vertical resolution in the ECHAM5 atmosphere model, J. Climate, 19, 3771-3791, 2006.

Sander, S. P., Friedl, R. R., Golden, D. M., Kurylo, M. J.,Huie, R. E., Orkin, V. L., Moortgart, G. K., Ravishankara, A. R., Kolb, C. E., Molina, M. J., and Finlayson-Pitts B. J.: Chemical Kinetics and Photochemical Data for Use in Atmospheric Studies, Evaluation Number 14, JPL Publication 02-25, 1 February 2003.

Sander, S. P., Friedl, R. R., Barker, J. R., Golden, D. M., Kurylo, M. J., Wine, P. H., Abbatt, J., Burkholder, J. B., Kolb, C. E., Moortgart, G. K., Huie, R. E., and Orkin, V. L.: Chemical Kinetics and Photochemical Data for Use in Atmospheric Studies, Evaluation Number 16, Supplement to Evaluation 15: Update of Key Reactions, JPL Publication 09-31, 2010.

Sander, S. P., Golden, D. M., Kurylo, M. J., Moortgat, G. K., Wine, P. H., Ravishankara, A. R., Kolb, C. E., Molina, M. J., FinlaysonPitts, B. J., Huie, R. E., Orkin, V. L., Friedl, R. R., and KellerRudek, H.: Chemical kinetics and photochemical data for use in atmospheric studies: evaluation number 15, JPL Publication 062, Jet Propulsion Laboratory, California Institute of Technology, Pasadena, CA, 2006.

Sander, R., Kerkweg, A., Jöckel, P., and Lelieveld, J.: Technical note: The new comprehensive atmospheric chemistry module MECCA, Atmos. Chem. Phys., 5, 445-450, doi:10.5194/acp-5445-2005, 2005. 
Sinnhuber, B.-M., Weber, M., Amankwah, A., and Burrows, J. P.: Total ozone during the unusual Antarctic winter of 2002, Geophys. Res. Lett., 30, 1580, doi:10.1029/2002GL016798, 2003.

Solomon, S., Garcia, R. R., Rowland, F. S., and Wuebbles, D. J.: On the depletion of Antarctic ozone, Nature, 321, 755-758, 1986.

Steck, T. and von Clarmann, T.: Constrained profile retrieval applied to the obervation mode of the Michelson Interferometer for Passive Atmospheric Sounding, Appl. Opt., 40, 3559-3571, 2001.

Stimpfle, R. M., Perry, R. A., and Howard, C. J.: Temperaturedependence of the reaction of $\mathrm{ClO}$ and $\mathrm{HO}_{2}$ radicals, J. Chem. Phys., 71, 5183-5190, 1979.

Tilmes, S., Müller, R., Grooß, J.-U., Höpfner, M., Toon, G. C., and Russell III, J. M.: Very early chlorine activation and ozone loss in the Arctic winter 2002-2003, Geophys. Res. Lett., 30, 2201, doi:10.1029/2003GL018079, 2003.

Toon, G. C., Farmer, C. B., Schaper, P. W., Lowes, L. L., and Norton, R. H.: Composition measurements of the 1989 Arctic winter stratosphere by airborne infrared solar absorption spectroscopy, J. Geophys. Res., 97, 7939-7961, 1992.

Traub, W. A., Johnson, D. G., and Chance, K. V.: Stratospheric Hydroperoxyl Measurements, Science, 247, 446-449, 1990.

Verronen, P. T., Seppälä, A., Kyrölä, E., Tamminen, J., Pickett, H. M., and Turunen, E.: Production of odd hydrogen in the mesosphere during the January 2005 solar proton event, Geophys. Res. Lett., 33, L24811, doi:10.1029/2006GL028115, 2006.

Verronen, P. T., Funke, B., López-Puertas, M., Stiller, G. P., von Clarmann, T., Glatthor, N., Enell, C.-F., Turunen, E., and Tamminen, J.: About the increase of $\mathrm{HNO}_{3}$ in the stratopause region during the Halloween 2003 solar proton event, Geophys. Res. Lett., 35, L20809, doi:10.1029/2008GL035312, 2008.

von Clarmann, T., Wetzel, G., Oelhaf, H., Friedl-Vallon, F., Linden, A., Maucher, G., Seefeldner, M., Trieschmann, O., and Lefèvre, F.: $\mathrm{ClONO}_{2}$ vertical profile and estimated mixing ratios of $\mathrm{ClO}$ and $\mathrm{HOCl}$ in winter Arctic stratosphere from Michelson Interferometer for Passive Atmospheric Sounding limb emission spectra, J. Geophys. Res., 102, 16157-16168, 1997.

von Clarmann, T., Glatthor, N., Grabowski, U., Höpfner, M., Kellmann, S., Kiefer, M., Linden, A., Mengistu Tsidu, G., Milz, M., Steck, T., Stiller, G. P., Wang, D. Y., Fischer, H., Funke, B., Gil-López, S., and López-Puertas, M.: Retrieval of temperature and tangent altitude pointing from limb emission spectra recorded from space by the Michelson Interferometer for Passive Atmospheric Sounding (MIPAS), J. Geophys. Res., 108, 4736, doi:10.1029/2003JD003602, 2003. von Clarmann, T., Glatthor, N., Höpfner, M., Kellmann, S., Ruhnke, R., Stiller, G. P., Fischer, H., Funke, B., Gil-López, S., and López-Puertas, M.: Experimental evidence of perturbed odd hydrogen and chlorine chemistry after the October 2003 solar proton events, J. Geophys. Res., 110, A09S45, doi:10.1029/2005JA011053, 2005.

von Clarmann, T., Glatthor, N., Grabowski, U., Höpfner, M., Kellmann, S., Linden, A., Mengistu Tsidu, G., Milz, M., Steck, T., Stiller, G. P., Fischer, H., and Funke, B.: Global stratospheric $\mathrm{HOCl}$ distributions retrieved from infrared limb emission spectra recorded by the Michelson Interferometer for Passive Atmospheric Sounding (MIPAS), J. Geophys. Res., 111, D05311, doi:10.1029/2005JD005939, 2006.

von Clarmann, T., Glatthor, N., Ruhnke, R., Stiller, G. P., Kirner, O., Reddmann, T., Höpfner, M., Kellmann, S., Kouker, W., Linden, A., and Funke, B.: HOCl chemistry in the Antarctic Stratospheric Vortex 2002, as observed with the Michelson Interferometer for Passive Atmospheric Sounding (MIPAS), Atmos. Chem. Phys., 9, 1817-1829, doi:10.5194/acp-9-1817-2009, 2009a.

von Clarmann, T., Höpfner, M., Kellmann, S., Linden, A., Chauhan, S., Funke, B., Grabowski, U., Glatthor, N., Kiefer, M., Schieferdecker, T., Stiller, G. P., and Versick, S.: Retrieval of temperature, $\mathrm{H}_{2} \mathrm{O}, \mathrm{O}_{3}, \mathrm{HNO}_{3}, \mathrm{CH}_{4}, \mathrm{~N}_{2} \mathrm{O}, \mathrm{ClONO}_{2}$ and $\mathrm{ClO}$ from MIPAS reduced resolution nominal mode limb emission measurements, Atmos. Meas. Tech., 2, 159-175, doi:10.5194/amt-2-1592009, 2009b.

Wang, D. Y., von Clarmann, T., Fischer, H., Funke, B., GarcíaComas, M., Gil-López, S., Glatthor, N., Grabowski, U., Höpfner, M., Kellmann, S., Kiefer, M., Koukouli, M. E., Lin, G., Linden, A., López-Puertas, M., Mengistu Tsidu, G., Milz, M., Steck, T., and Stiller, G. P.: Longitudinal variations of temperature and ozone profiles observed by MIPAS during the Antarctic stratosphere sudden warming of 2002, J. Geophys. Res., 110, D20101, doi:10.1029/2004JD005749, 2005.

World Meteorological Organization: Scientific Assessment of Ozone Depletion: 2006, Global Ozone Research and Monitoring Project - Report No. 50, Geneva, Switzerland, 572 pp., 2007.

World Meteorological Organization: Scientific Assessment of Ozone Depletion: 2006, Global Ozone Research and Monitoring Project - Report No. 52, Geneva, Switzerland,2.42 pp., 2011. 